\title{
Laboratory Test for Unstable Ductile Fracture in Mild Steel ${ }^{*}$
}

\author{
By Masao OGASAWARA, ${ }^{* *}$ Hiroshi MIMURA ${ }^{* *}$ and \\ Shoichi NAKANISHI**
}

\section{Synopsis}

A laboratory test method for unstable ductile fracture of mild steels was developed. Shear crack was initiated from very deep notch. Some devices such as pipe tab are employed to reduce the stiffness of the system enough to make shear crack continue to grow in an unstable manner.

Four kinds of pipe material wre tested using this test method and three of them of lower ductility showed unstable ductile fracture. Fracture toughness of these steels for the onset of unstable ductile fracture was obtained and was correlated successfully to ${ }_{v} E$ shelf, shelf energy of Charpy test, which was quite similar to those obtained by Eiber, et al., with the full scale burst test of pipes.

\section{Introduction}

It is well known for ultra high strength steel that unstable fracture takes place in shear mode as well as in cleavage. Generally, the fracture toughness in shear mode increases quite rapidly with the decrease in yield point, in other words, steels of low strength have less tendency to unstable fracture than high strength steels. It has not been well understood whether the unstable ductile fracture takes place in mild steels. It is thought that the low strength and high ductility of mild steel cause a considerable amount of plastic deformation around crack tip which prevents the further cumulative damage at the tip of a crack, and makes it difficult for the crack to propagate. On the contrary, it might be expected from the standpoint of R-curve concept that the unstable ductile fracture takes place even in mild steel when crack length is long enough. Recently, it was found ${ }^{1)}$ that ductile fracture propagates over long distances in gas pipelines. Therefore, it can be expected that the mild steel fractures in an unstable manner by a laboratory test in which the conditions similar to gas pipelines are realized. The purpose of the present work is to develop such a laboratory test method; the developed one is a wide plate notched tensile test characterized with very low stiffness and large stress intensity factor.

\section{Test Methods}

It is useful, for the development of a new test method with the purpose described above, to consider the condition under which unstable ductile fracture occurs in gas pipe lines. Firstly, the stress relaxes only a little after the passage of a crack due to high compressibility of gas. ${ }^{1)}$ Secondly, the stress intensity factor is effectively quite large due to "the bulging effect" or "the flapping action" of the walls of the broken pipes. ${ }^{2)}$ A high design stress such as $80 \%$ of $\sigma_{y}$ and large diameters of pipes are considered to contribute to the occurrence of this type of fracture. ${ }^{10)}$ Finally, the steels used for pipes sometimes have low notch ductility because the crack path is usually in the rolling direction of controlled rolled plates. In the present experiment, the following test method is used to simulate the above mentioned factors. Load is applied to a specimen through pipes by which the displacement and load drop following crack extension are much absorbed due to their large compliance. ${ }^{3)}$ Two sets of "pipe tabs" were employed in accordance with notch ductility of tested specimens. Geometry of each pipe tab is shown in Fig. 1. The stiffness of the tab was shown to have an enough low value as shown in Appendix I. Specimens cut out of pipes to be tested were rectangular with the original curvature and welded to the tabs. Deep side-notches were cut. The deep notch and curvature result in the large stress intensity factor at the notch tip. Larger specimen was used for more ductile materials, because longer initial cracks for the larger stress intensity is necessary to realize the onset of unstable propagation of the ductile crack. The crack speed was tried to be measured with timing wire, though, not every trial was succeeded. Several kinds of materials having various notch ductilities were investigated. The least ductile material was prepared by laboratory

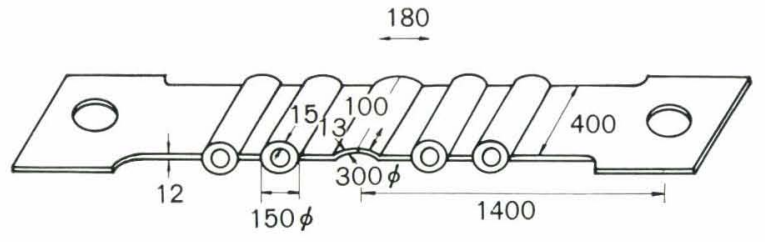

Fig. 1 (a). Test assembly for Steels \#A and \#B

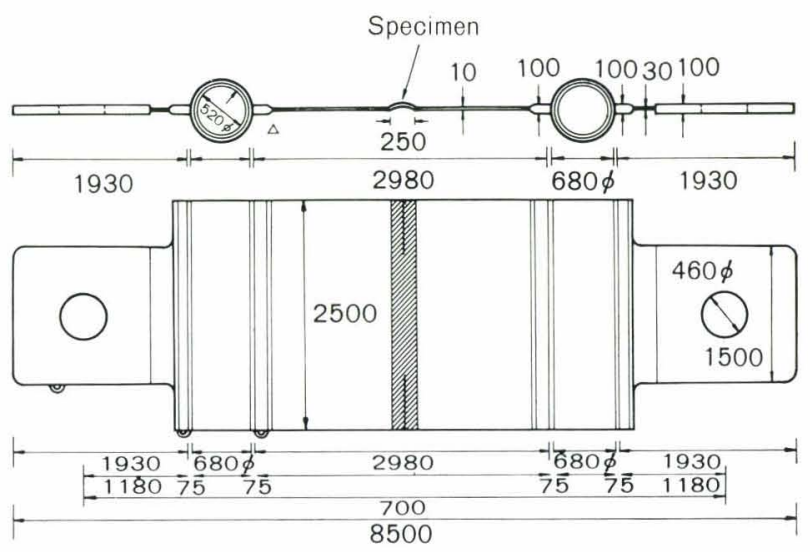

Fig. 1 (b). Test assembly for Steels \#C and \#D

* Presented at the 87th ISIJ Meeting, April, 1974, at Nippon University, Narashino 275. Manuscript received November 9, 1976.

** Products R \& D Laboratories, Nippon Steel Corp., Fuchinobe, Sagamihara 226. 
furnace. It had a high S content of $0.3 \%$ and was hot-rolled with low finishing temperature and coldbent. It showed an extremely low shelf energy in $\mathrm{V}$ notched Charpy test. The others were chosen from the commercial pipes. The first was the pipe of X-52 grade in API specification having a very low shelf energy. The shelf energy of about $3 \mathrm{~kg} \cdot \mathrm{m}$ of this specimen is considered to be near the lower limit in the similar kind of commercial materials. The second was STS 49 in JIS spec. of the usual shelf energy and the third was 18-8 stainless steel pipe which is an example of highly ductile material. The chemical composition and the mechanical properties are given in
Table 1

\section{Test Results}

All the test results are summarized in Tables 2 to 5 .

\section{Steel \#A $(0.3 \% \mathrm{~S}$ material $)$}

The specimen was broken under the net stress* below yield point. The crack propagated rapidly. Only shear fracture was found on the fracture surfaces. Then, it can be said that the unstable ductile fracture occurs in mild steels if some conditions are satisfied. The crack did not propagate when the applied stress was below some critical stress even if it was initiated

Table 1. Chemical and mechanical properties of the specimens

\begin{tabular}{|c|c|c|c|c|c|c|c|c|c|c|c|c|c|c|}
\hline \multirow{2}{*}{ Specimens } & \multicolumn{10}{|c|}{ Chemical composition (\%) } & \multicolumn{4}{|c|}{$\begin{array}{l}\text { Mechanical properties for } \\
\text { circumferential direction }\end{array}$} \\
\hline & C & $\mathrm{Si}$ & $\mathrm{Mn}$ & $\mathrm{P}$ & $\mathrm{S}$ & $\mathrm{V}$ & $\mathrm{Cr}$ & $\mathrm{Al}$ & $\mathrm{Cu}$ & $\mathrm{Ni}$ & $\begin{array}{c}\text { Y.S. } \\
\left(\mathrm{kg} / \mathrm{mm}^{2}\right)\end{array}$ & $\begin{array}{c}\text { T.S. } \\
\left(\mathrm{kg} / \mathrm{mm}^{2}\right)\end{array}$ & $\begin{array}{l}\text { El. } \\
(\%)\end{array}$ & $\begin{array}{c}\text { Charpy } \\
\text { shelf } \\
(\text { Standard } \\
\text { size })(\mathrm{kg} \cdot \mathrm{m})\end{array}$ \\
\hline $\begin{array}{c}\# \mathrm{~A} \\
\mathrm{X}-65\end{array}$ & 0.09 & 0.19 & 1.30 & 0.009 & 0.33 & 0.042 & - & - & - & - & 53 & 57 & 7 & 0.45 \\
\hline $\begin{array}{l}\# \mathrm{~B} \\
\mathrm{X}-52\end{array}$ & $\begin{array}{c}0.177 \\
? \\
0.190\end{array}$ & 0.29 & $\frac{1.12}{2.13}$ & $\begin{array}{c}0.014 \\
? \\
0.023\end{array}$ & $\begin{array}{c}0.012 \\
? \\
0.015\end{array}$ & $\begin{array}{l}0.045 \\
? \\
0.05\end{array}$ & - & $\begin{array}{c}0.018 \\
? \\
0.023\end{array}$ & - & $<0.01$ & $41 \sim 45$ & $56 \sim 60$ & $30 \sim 34$ & $2.8 \sim 3.5$ \\
\hline $\begin{array}{l}\text { \#C } \\
\text { STS } 49\end{array}$ & 0.27 & 0.32 & 0.88 & 0.014 & 0.009 & - & - & - & 0.02 & - & 38 & 58 & 25 & 10 \\
\hline $\begin{array}{c}\text { \#D } \\
\text { SUS } 304\end{array}$ & 0.05 & 0.59 & 1.12 & 0.025 & 0.008 & - & 18.4 & - & - & 9.6 & 22 & 57 & 71 & $\begin{array}{c}12 \\
\left(6.0^{*}\right)\end{array}$ \\
\hline
\end{tabular}

* The value is converted from the results of $1 / 2$-size Charpy test.

Table 2. Test results of Steel \#A (X-65, $406 \dot{\phi} \times 13 \mathrm{t})$

\begin{tabular}{|c|c|c|c|c|c|c|c|c|}
\hline \multirow{2}{*}{$\begin{array}{l}\text { Speci- } \\
\text { mens } \\
\text { No. }\end{array}$} & \multirow{2}{*}{$\begin{array}{l}\text { Speci- } \\
\text { mens } \\
\text { shape }\end{array}$} & \multirow[b]{2}{*}{$\begin{array}{c}\text { Tab } \\
\text { shape }\end{array}$} & \multirow[b]{2}{*}{$\begin{array}{l}\text { Slow growth } \\
(\mathrm{mm})\end{array}$} & \multicolumn{3}{|c|}{ Onset of propagation } & \multirow[b]{2}{*}{ Fracture mode } & \multirow[b]{2}{*}{ Test method } \\
\hline & & & & $\begin{array}{c}\text { Net } \\
\text { stress } \\
\left(\mathrm{kg} / \mathrm{mm}^{2}\right.\end{array}$ & $\begin{array}{c}\text { Onset } \\
K_{c} \\
\left(\mathrm{~kg} \cdot \mathrm{mm}^{-3 / 2}\right)\end{array}$ & $\begin{array}{c}\text { Speed } \\
(\mathrm{m} / \mathrm{sec})\end{array}$ & & \\
\hline \#A-1 & Curved & Pipes & $\sim 10$ & 27 & 370 & 23 & Unstable propagate & Tension \\
\hline \#A-2 & " & $”$ & $\sim 10$ & 21 & 290 & 50 & $"$ & $"$ \\
\hline \#A-3 & Flat & , & $\sim 20$ & 42 & 420 & 50 & , & ” \\
\hline \#A-5 & ” & $"$ & ” & 23 & - & - & $"$ & " \\
\hline \multirow{2}{*}{ \#A-6 } & \multirow[b]{2}{*}{ " } & \multirow{2}{*}{ Pipes } & \multirow{2}{*}{-} & 23 & - & - & Not propagate & Hammer blow \\
\hline & & & & 27 & 370 & 20 & Unstable propagate & Tension \\
\hline \multirow{2}{*}{ \#A-7 } & \multirow[b]{2}{*}{ ” } & \multirow[b]{2}{*}{ ” } & \multirow{2}{*}{-} & 27 & - & - & Not propagate & Hammer blow \\
\hline & & & & 30 & 410 & 35 & Unstable propagate & Tension \\
\hline
\end{tabular}

Table 3. Test results of Steel \#B (X-52, $609 \phi \times 13 \mathrm{t})$

\begin{tabular}{|c|c|c|c|c|c|c|c|}
\hline \multirow{2}{*}{$\begin{array}{l}\text { Speci- } \\
\text { mens } \\
\text { No. }\end{array}$} & \multirow{2}{*}{$\begin{array}{l}\text { Speci- } \\
\text { mens } \\
\text { shape }\end{array}$} & \multirow[b]{2}{*}{$\begin{array}{l}\text { Tab } \\
\text { shape }\end{array}$} & \multirow[b]{2}{*}{$\begin{array}{l}\text { Slow growth } \\
(\mathrm{mm})\end{array}$} & \multicolumn{2}{|c|}{ Onset of propagation } & \multirow[b]{2}{*}{ Fracture mode } & \multirow[b]{2}{*}{ Test method } \\
\hline & & & & $\begin{array}{cc}\text { Net } & \text { Onset } \\
\text { stress } & K_{c} \\
\left(\mathrm{~kg} / \mathrm{mm}^{2}\right) & \left(\mathrm{kg} \cdot \mathrm{mm}^{-3 / 2}\right)\end{array}$ & $\begin{array}{l}\text { Speed } \\
(\mathrm{m} / \mathrm{sec})\end{array}$ & & \\
\hline \#B-1 & Curved & Pipes & 20 & 730 & - & Unstable propagate & Simple tension \\
\hline \#B-2 & $"$ & $"$ & 30 & 760 & - & $"$ & $"$ \\
\hline \#B-3 & , & $"$ & , & 860 & - & ” & ” \\
\hline
\end{tabular}

* Net stress is load over cross sectional area between notches. 
Table 4. Test results of Steel \#C (STS 49, $356 \phi \times 15 \mathrm{t}$ )

\begin{tabular}{|c|c|c|c|c|c|c|c|c|c|}
\hline \multirow{2}{*}{$\begin{array}{l}\text { Speci- } \\
\text { mens } \\
\text { No. }\end{array}$} & \multirow{2}{*}{$\begin{array}{l}\text { Speci- } \\
\text { mens } \\
\text { shape }\end{array}$} & \multirow[b]{2}{*}{$\begin{array}{l}\text { Tab } \\
\text { shape }\end{array}$} & \multirow[b]{2}{*}{$\begin{array}{l}\text { Slow growth } \\
(\mathrm{mm})\end{array}$} & \multicolumn{3}{|c|}{ Onset of propagation } & \multirow[b]{2}{*}{ Fracture mode } & \multirow[b]{2}{*}{$\begin{array}{l}\text { Test } \\
\text { method }\end{array}$} & \multirow[b]{2}{*}{$\begin{array}{l}\text { Test } \\
\text { temp. } \\
\left({ }^{\circ} \mathrm{C}\right)\end{array}$} \\
\hline & & & & $\begin{array}{c}\text { Net } \\
\text { stress } \\
\left(\mathrm{kg} / \mathrm{mm}^{2}\right)\end{array}$ & $\begin{array}{c}\text { Onset } \\
K_{e} \\
\left(\mathrm{~kg} \cdot \mathrm{mm}^{-3 / 2}\right) \\
\end{array}$ & $\begin{array}{l}\text { Speed } \\
(\mathrm{m} / \mathrm{sec})\end{array}$ & & & \\
\hline \#C-1 & Curved & Multi-pipes & 50 & 48 & 1250 & - & Unstable propagate & Tension & +80 \\
\hline \#C-2 & $"$ & $”$ & 100 & 51 & 1310 & 16 & $"$ & " & +15 \\
\hline \#C-3 & $"$ & ” & 100 & 50 & 1300 & - & $"$ & $"$ & +15 \\
\hline
\end{tabular}

Table 5. Test result of Steel \#D (SUS 304, $100 \phi \times 5.7 \mathrm{t}$ )

\begin{tabular}{c|c|c|c|c|c|c}
\hline \multirow{2}{*}{$\begin{array}{c}\text { Specimens } \\
\text { No. }\end{array}$} & $\begin{array}{c}\text { Specimens } \\
\text { shape }\end{array}$ & Tab shape & $\begin{array}{c}\text { Initiation } \\
\left(\mathrm{kg} / \mathrm{mm}^{2}\right)\end{array}$ & $\begin{array}{c}\text { Max. load } \\
\left(\mathrm{kg} / \mathrm{mm}^{2}\right)\end{array}$ & Fracture mode & Test method \\
\hline \#D-1 & Curved & Multi-pipes & 19 & 58 & Stable slow growth & Tension \\
\#D-2 & $\#$ & $\ldots$ & 13 & 55 & $\ldots$ & $\#$ \\
\hline
\end{tabular}

by the hammer blow. The critical stress was found to be equal to the stress at the oneset of unstable propagation which was obtained simply by increasing load, i.e., fracture toughness, $K_{c}$, for the propagation differs little from that for the initiation.

When rigid tabs were used, crack grew slowly following the movement of pin-chuck of tensile rigs. When a flat specimen was tested instead of the curved one, the fracture stress increased by a large amount. From these experiments, it can be understood that the present test method is quite effective to realize unstable ductile fracture in the laboratory.

\section{Steel \#B ( $X$-52 pipes)}

The slow growth was observed preceding the unstable crack growth in this specimen. Unstable fracture occurred at a stress nearly equal to the yield point. It can be seen from the comparison between Steels \#A and \#B that fracture stress increased with notch ductility.

\section{Steel \#C (STS 49)}

From the test results of Steel \#B, it was inferred that much higher stress intensity factor, i.e., longer notch and lower stiffness, was necessary for the realization of unstable fracture of Steel \#C. Ultra-wide plate specimens and multi-layered pipe tabs were thus employed. Unstable fracture, however, took place at a stress between yield point and tensile strength. Therefore, the curvature of the specimen was lost at fracture. A crack started to grow at a stress far below yield point and continued to grow slowly to about $100 \mathrm{~mm}$ in length, before rapid fracture occurred. The test temperature did not influence on the fracture stress.

\section{Steel \#D (18-8 Stainless Steel)}

For this specimen, unsrable fracture was not observed. Fracture occurred following necking, i.e., plastic instability. Fracture stress was nearly equal to the tensile strength.

The cross sectional view of the fracture surface for these four specimens is shown in Photo. 1. Reduction in thickness was hardly observed in Steel \#A and the fracture surface is nearly perpendicular to the specimen surface. In the case of Steel \#C, however, fracture surface is of a smooth $45^{\circ}$ propagating shear mode, on the other hand, the mixture of shear and cup-andcone mode was found for Steel \#D. The reduction in thickness is shown in Fig. 2.

Critical stress intensity factors are calculated by the following equation and given in Tables 2 to 5 .

$$
\begin{aligned}
& K_{c}=\sigma_{f} \sqrt{\pi c} \cdot g(\lambda) \cdot f(\gamma) \\
& \quad f(\gamma)=\sqrt{1 / \gamma \cdot \tan \gamma}, \quad \gamma=\pi c / b
\end{aligned}
$$

where, $K_{c}$ : is critical stress intensity factor,

$\sigma_{f}:$ stress at the onset of crack propagation,

$c$ : half crack length,

$g(\lambda)$ : correction factor for curvature, and

$f(r)$ : correction factor for plate width, $b$.

The expression of $g(\gamma)$ is given in Appendix II. This correction factor was not applied to Steel \#C, because the curvature was lost at fracture in this specimen.

\section{Discussion}

The crack in Steel \#A propagated rapidly under a stress below the yield point without noticeable reduction in thickness. Therefore, it can be said that unstable ductile fracture does occur in mild steels if its notch ductility is low enough.

Then, let's examine fracture in mild steel of usual ductility. The fracture stress was nearly equal to or little higher than $\sigma_{Y}$ in Steels \#B and \#C, respectively. The fracture may be termed as unstable ductile one, if the following conditions are satisfied.

(1) Commulative damage around the crack tip attains to its critical value successively

(2) Crack propagates by the consumption of released energy due to crack extension

Steel \#C was fractured with the above features as discussed in the following. Fracture stress was surely above yield stress but fairly below tensile strength. In other words, rapid crack propagation observed in Steel \#C was not due to the apparent result of plastic instability or necking which is expected to occur beyond the tensile strength. Further the fracture surface was 


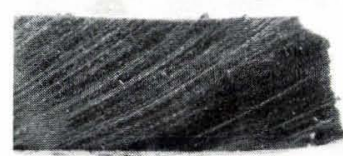

(Steel \#A)

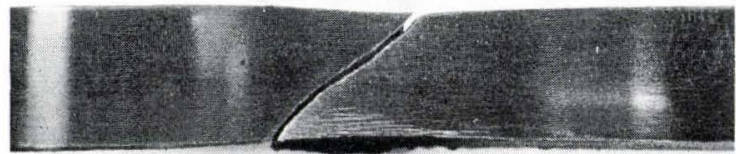

STS 49

(Steel \#C)

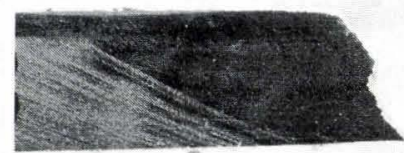

(Steel \#B)

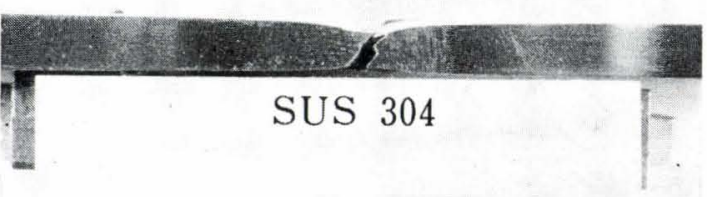

(Steel $\# \mathrm{D})$

Photo. 1. Cross sectional view of the broken specimens

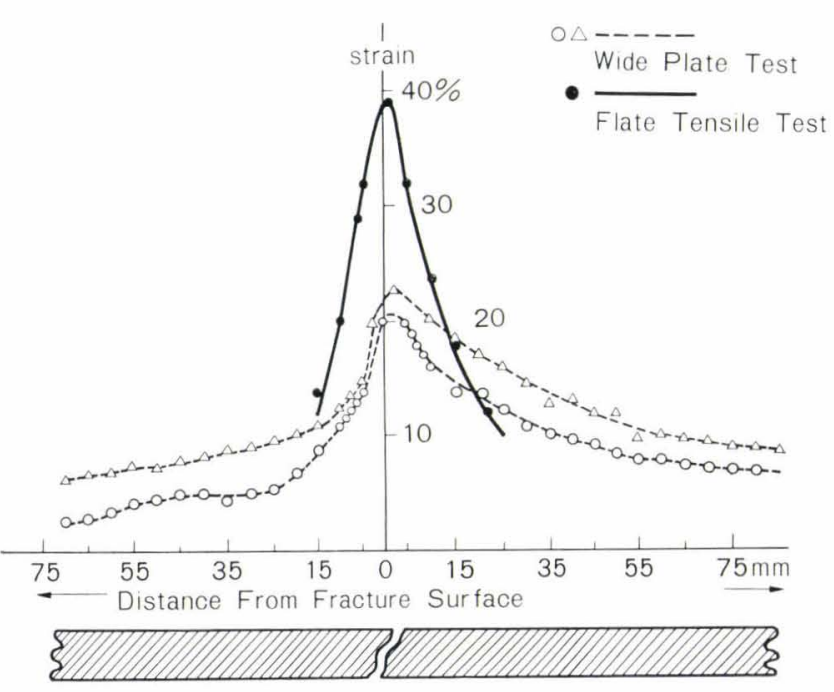

Fig. 2 (a). Reduction in thickness of Steel \#C

that of "propagating shear fracture", $45^{\circ}$ shear to the tensile stress, with less reduction in thickness which is just like that observed in the field burst test of pipes. Reduction in thickness in Fig. 2 shows that unstable fracture surface of Steel \#C gave much lower reduction in thickness than that of flat tensile test specimen. These features show clear contrast with those of Steel \#D. In the case of stainless steel, a crack grew continuously in the slow manner and reduction in thickness obtained was almost the same as that of flat tensile test. The fracture stress is nearly equal to the tensile strength.

From the above discussion, it will be reasonable to conclude that Steel \#C showed the unstable ductile fracture. It might need longer initial crack length and consequently wider specimen width to realize the low stress fracture in Steel \#D as is explained concep-

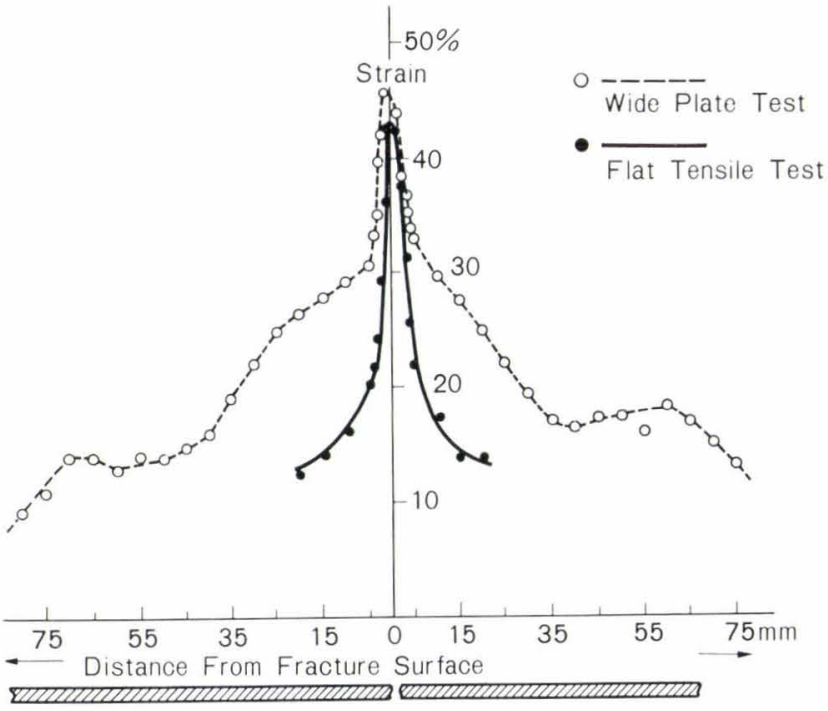

Fig. 2 (b). Reduction in thickness of Steel \#D

tionally in Fig. 3 by means of R-curve approach, ${ }^{4)}$ which is also useful for the explanation of slow crack growth observed in Steels \#B and \#C.

Fracture toughness for onset of unstable ductile fracture can be approximately calculated by Eq. (1).* Eiber, et al. obtained $K_{c}$ value for the onset of unstable ductile fracture which was assumed to be equal to that of arrest. The assumption is shown to be reasonable from the present work. They showed that $K_{c}$ has a good correlation to ${ }_{v} E$ shelf, upper shelf energy of V-notch Charpy impact transition curve. ${ }^{5)}$ The correlation between $K_{c}$ and ${ }_{v} E$ shelf was examined also in this work. The similar conclusion was obtained in the present case as shown in Fig. 4, in which the data by other authors are also plotted. ${ }^{6)}$ It can be seen that all the data points fall in some narrow band.

* Equation (1) is beyond its valid application range in the exact sense when fracture stress is around yield point. Therefore, the present value for $K_{c}$ is only approximate and probably under estimated. To obtain valid value, a much larger specimen will be necessary. 

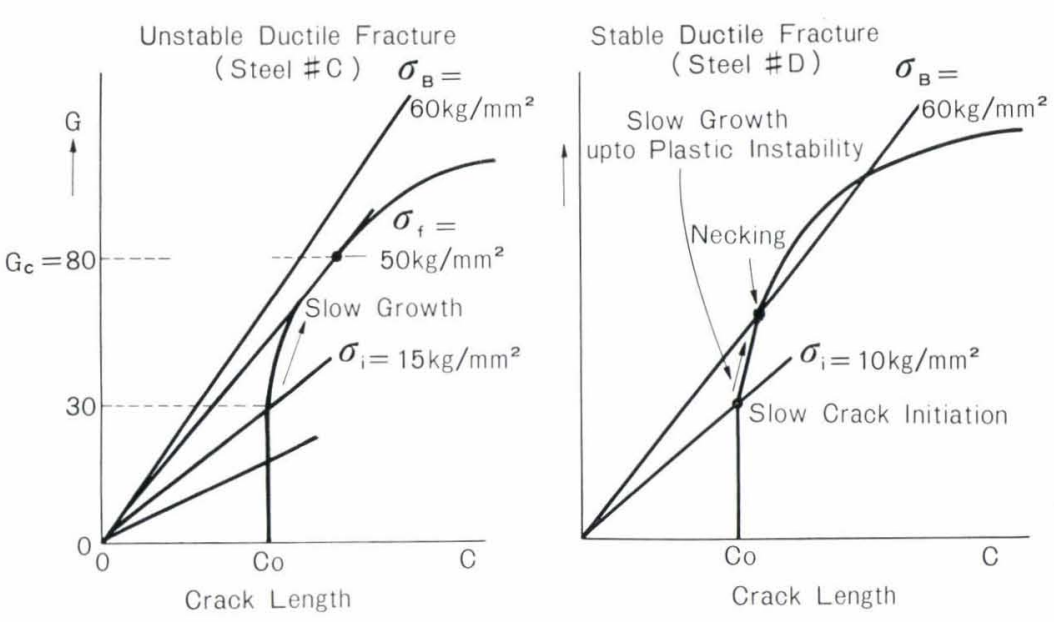

Fig. 3. Schematic representation of R-curve approach to unstable ductile fracture

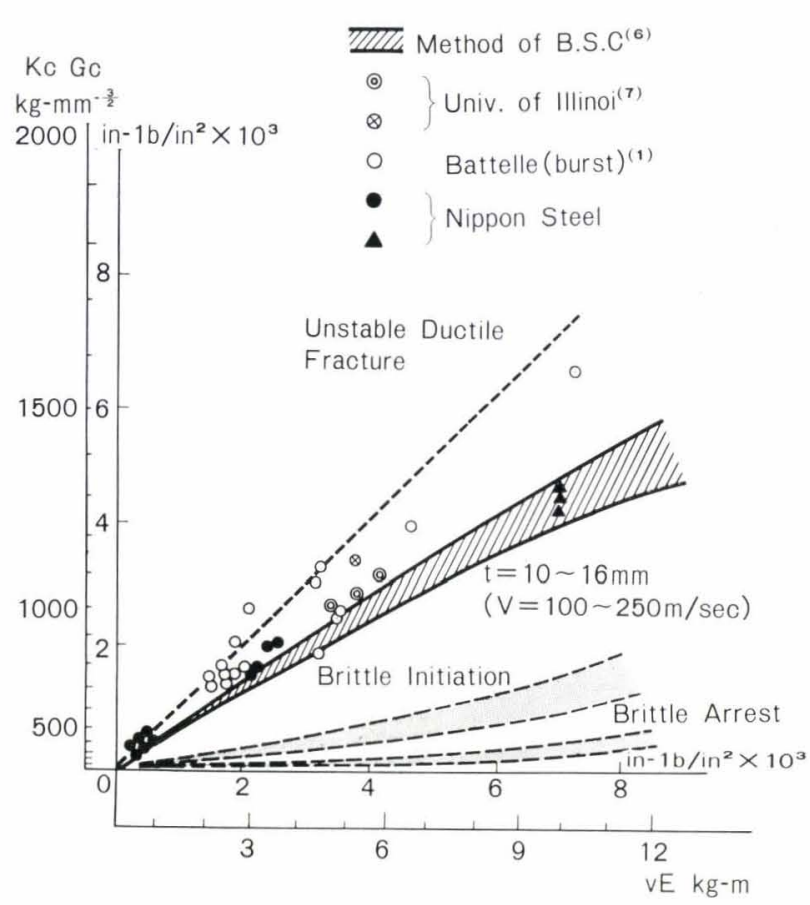

Fig. 4. Correlation between Charpy absorption energy and the resistance of unstable fracture

\section{Conclusions}

The results are summarized as follows.

(1) Mild steel can be fractured in an unstable ductile manner when the stress intensity at the crack tip is larger enough than the notch ductility of the material. The laboratory test for it was developed successfully.

(2) $K_{e}$ value for such fracture was obtained and correlated with the Charpy shelf energy.

\section{Acknowledgements}

The test for Steels \#C and \#D was conducted as a part of research of 4UB Committee of Atomic Energy Commission in the Japan Welding Engineering Society. Authors' thanks are due to Professor Y. Ando, Chairman of the Committee.

The authors also would like to express their thanks to Dr. T. Ikeno, Director of Products Research and Development Laboratories in Nippon Steel Corp., and
Dr. S. Kanazawa, General Manager of Products Research and Development Laboratories in Nippon Steel Corp. for their encouragement in the course of this experiment.

\section{REFERENCES}

1) A. R. Duffy: AGA Symposium on Line Pipe Research, American Gas Association Report, Nov., (1965), 43.

2) K. D. Ives, A. K. Shoemaker and R. F. McCartney: U.S. Steel Technical Report, March, (1974), No. 59. 018-015 (1).

3) M. Ogasawara, H. Mimura and K. Ishizaki: Int'l Symp. on Crack Propagation in Pipelines, Newcastle upon Tyne, Apr., (1974), Paper 10.

4) Fracture Toughness Evaluation by R-curve Method, ASTM Special Publ., 527, (1973).

5) W.A. Maxey, J. F. Kiefner, R. J. Eiber, and A. R. Duffy: The 5th Int. Symp. on Fracture Mechanics Aug., (1971).

6) J. A. Dick, P. Mc. Jamieson and E. F. Walker: Int'l Symp. on Crack Propagation in Pipelines, Newcastle upon Tyne, England, Apr., (1974), Paper 16.

7) R. J. Podlasek: Dissertation, Univ. of Illionois, (1973).

8) E. S. Folias: Engineering Fracture Mechanics, 2 (1970), 151.

9) J. L. Sanders: Trans. ASME Series E., 27 (1960), No. 2, 352.

10) H. Mimura and M. Ogasawara: Int'l Symp. on Crack Propagation in Pipelines, Newcastle upon Tyne, Apr., (1974), Paper 14.

\section{Appendix}

\section{Stiffness of Multi-pipe Tab}

The relation between displacement and load is written for multi-pipe tab as follows:

$$
\delta=\left(\frac{L_{2}}{E t b}+0.85 \frac{R^{3}}{E b h^{3}}\right) \cdot p
$$

The stiffness is defined by

$$
m=\frac{p}{\delta}
$$

where,

$$
\begin{array}{cl}
\delta: & \text { displacement } \\
E: & \text { Young's modulus } \\
p: & \text { load } \\
b: & \text { specimen width }
\end{array}
$$




$$
\begin{aligned}
R: & \text { average radius of pipes on tab } \\
m: & \text { stiffness of tab } \\
L_{2}: & \text { length of flat parts of tab } \\
t: & \text { thickness of flat parts } \\
h: & \text { thickness of pipes }
\end{aligned}
$$

Coefficient of stress relaxation, $\alpha$, is expressed as

$$
\alpha=\frac{1}{1+\frac{m_{0}}{m}} \cong 0.1
$$

where, $m_{0}$ is the stiffness of flat tab.

Load relaxation due to crack advance is given as

$$
\frac{p}{p_{0}}=\frac{1}{1+\alpha \frac{2 m\left(C_{0}\right)}{E p_{0}^{2}} \int_{c_{0}}^{c} K^{2} d c}
$$

where, $\alpha=0$ corresponds to the load constant condition and $\alpha=1$, to the displacement constant condition.

II. Calculation of $K$ Value for Curved Specimen under Tension

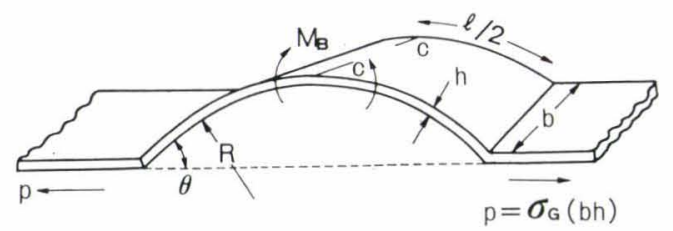

$M_{B}$ is calculated under the assumption that $\theta$ is not changed during the tensile test, and shown as,

$$
M_{B}=\frac{1}{24} \cdot \sigma_{G} \cdot h \frac{l^{2}}{R}
$$

From linear fracture mechanics, stress distribution around notch tip under tension is given as follows:

$$
\begin{aligned}
\sigma_{x}^{T} & =\frac{K_{I}}{\sqrt{ } 2 \pi r} \cdot \cos \frac{\theta}{2} \cdot\left[1-\sin \frac{\theta}{2} \cdot \sin \frac{3}{2} \theta\right] \\
\sigma_{y}^{T} & =\frac{K_{I}}{\sqrt{ } 2 \pi r} \cdot \cos \frac{\theta}{2} \cdot\left[1+\sin \frac{\theta}{2} \cdot \sin \frac{3}{2} \theta\right] \\
\tau_{x y}^{T} & =\frac{K_{I}}{\sqrt{ } 2 \pi r} \cdot \sin \frac{\theta}{2} \cdot \cos \frac{\theta}{2} \cdot \cos \frac{3}{2} \theta \ldots \ldots \ldots
\end{aligned}
$$

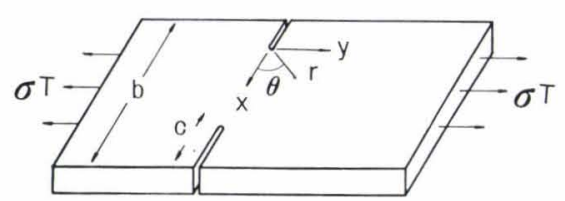

where, $\sigma_{x}^{T}, \sigma_{y}^{T}, \tau_{x y}^{T}$ : stress components under tension load, $\sigma^{T}$.

$$
\begin{aligned}
& K_{I}=\sigma^{T} \sqrt{\pi c} \cdot f(\gamma) \\
& f(\gamma)=\left(\frac{1}{\gamma} \tan \gamma\right)^{1 / 2}, \quad \gamma=\pi c / b
\end{aligned}
$$

Stress distribution around notch tip under bending load is given as:

$$
\begin{aligned}
\sigma_{\tau}^{B} & =\frac{7+\nu}{2(3+\nu)} \cdot \frac{K_{B}}{\sqrt{ } 2 \pi r} \cdot \frac{z}{h}\left[\frac{3+5 \nu}{7+\nu} \cdot \cos \frac{\theta}{2}-\cos \frac{3}{2} \theta\right] \\
\sigma_{\theta}^{B} & =\frac{7+\nu}{2(3+\nu)} \cdot \frac{K_{B}}{\sqrt{ } 2 \pi r} \cdot \frac{z}{h}\left[\frac{5+3 \nu}{7+\nu} \cdot \cos \frac{\theta}{2}+\cos \frac{3}{2} \theta\right] \\
\tau_{r \theta}^{B} & =\frac{7+\nu}{2(3+\nu)} \cdot \frac{K_{B}}{\sqrt{ } 2 \pi r} \cdot \frac{z}{h}\left[-\frac{1+\nu}{7+\nu} \cdot \sin \frac{\theta}{2}+\sin \frac{3}{2} \theta\right]
\end{aligned}
$$

where, $\nu$ : poisson's ratio

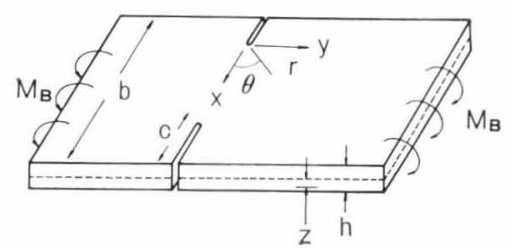

$\sigma_{r}^{\theta}, \sigma_{\theta}^{B}, \tau_{r \theta}^{B}$ : stress components under bending load, $M_{B}$, respectively,

$$
K_{B}=\frac{6 M_{B}}{h^{2}} \cdot \sqrt{\pi c} \cdot f(\gamma)
$$

Thus, the total energy of the system under both tensile and bending load which was discussed by Sanders $^{9)}$ and Folias ${ }^{8)}$ is given as follows:

$$
\begin{aligned}
U_{\text {system }}= & U_{0}+\gamma^{*}(2 A+Q h)+4 \gamma^{*} C h \\
& -2 \frac{C}{8 G} \int_{-h / 2}^{h / 2} \int_{0}^{C} \int_{-\pi}^{\pi}\left\{\begin{array}{l}
1-\nu \\
1+\nu
\end{array}\left(\sigma_{x}+\sigma_{y}\right)^{2}\right. \\
& \left.+\left(\sigma_{x}-\sigma_{y}\right)^{2}+\left(2 \tau_{x y}\right)^{2}\right\} r d r d \theta d Z \ldots \ldots \ldots \ldots . .
\end{aligned}
$$

where, $\quad \sigma_{x}=\sigma_{x}^{T}+\sigma_{x}^{B}$

$$
\begin{aligned}
\sigma_{y} & =\sigma_{y}^{T}+\sigma_{y}^{B} \\
\tau_{x y} & =\tau_{x y}^{T}+\tau_{x y}^{B} \\
\gamma^{*}: & \text { surface energy per unit area } \\
U_{0}: & \text { reference constant energy } \\
Q: & \text { periphery } \\
A: & \text { surface area of the specimen }
\end{aligned}
$$

For crack instability

$$
\frac{\partial U}{\partial C}=0
$$

which reduced to

$$
K=K_{I} \sqrt{1+\left(\frac{1+\nu}{5-3 \nu}\right) \cdot \frac{\frac{29}{3}+2 \nu-\nu^{2}}{(3+\nu)^{2}}\left(\frac{K_{B}}{K_{I}}\right)^{2}}
$$

here, suppose $\nu=1 / 2$ (poisson's ratio for plastic region)

$$
K=K_{I} \sqrt{1+0.023\left(\frac{l^{2}}{R h}\right)^{2}}
$$

Equation (A-11) was used for calculation of $K_{c}$ in the present work. 